\title{
Investment Advice for CNOOC Based on External Risks and Analysis of the Company's Financial Situation
}

\author{
Denggyao Luo ${ }^{1, \mathrm{a},{ }^{*},}$ Genben Xiang ${ }^{2, \mathrm{~b},{ }^{*},}$ Chengming $\mathrm{Zhu}^{3, \mathrm{c}, *, \uparrow}$
}

\author{
${ }^{I}$ Department of physics, Wuhan University, Wuhan 430072, China \\ ${ }^{2}$ Hust School of Economics, Huazhong University of Science and Technology, Wuhan, 430000, China \\ ${ }^{3}$ University Of Warwick, Scarman Rd, Coventry CV4 7AL, United Kingdom \\ *Corresponding author.Email: ${ }^{a} 2018302020118 @$ whu.edu.cn, ${ }^{b}$ u201916536@hust.edu.cn, \\ ${ }^{c}$ ChengmingZhu@Warwick.ac.uk \\ ${ }^{\top}$ These authors contributed equally.
}

\begin{abstract}
Trade frictions between China and the U.S. are still escalating in 2020, and the oil industry's capacity is in a deep recession. China National Offshore Oil Corporation was influenced by both backgrounds. Therefore, we want to analyze the company's prospects and advise investors. We analyze the company's business position, financial data, and combine industry background to predict the company's future trends. This is done by studying the company's financial indicators in recent years, understanding changes in capacity based on the company's annual reports, combined with stock price changes and news to understand the risks facing the company. Ultimately, we realized that CNOOC's operating capacity was above the market average. In the long run, CNOOC's capacity will steadily increase and external risks will be relatively manageable. Investors can consider CNOOC as a medium- and long-term value investment target. After analysis, we have concluded that CNOOC's profitability is better than the market average and its profitability is the opposite. Externally, there are still some medium- and long-term risks, but there is potential for growth in the future and it is worth targeting for long-term investment.
\end{abstract}

Keywords: China National Offshore Oil Corporation, COVID-19, analysis of corporation

\section{INTRODUCTION}

In 2020, the outbreak of Covid-19 severely impacted the global economy and the international oil market. The decline in world oil demand was the highest in history, down 8.8 million barrels per day from 2019. Global oil demand ushered in the largest shrinkage in history. At the same time, with the advent of the era of clean energy and digitalization, major international oil companies are facing a series of increasingly severe challenges [1]. As the electrification process continues to advance, the structure of the global energy system will undergo a fundamental adjustment. Renewable energy consumption will continue to grow strongly in 2020, accounting for more than $40 \%$ of the global primary energy growth, and energy demand will be more diversified [2] and customer demand-oriented. On the other hand, with the increasingly severe global climate change situation, governments of various countries are paying more and more attention to low-carbon clean energy, and oil companies are facing tremendous pressure for the energy transition.

Aside from COVID-19, the oil industry was also influenced by the Russia-Saudi Arabia oil price war.[3]. The low demand for production and transportation caused by global lockdown led to a decrease in oil price in early 2020. It was estimated by International Energy Agency (IEA) that the oil demand growth will decrease to 825,000 barrels per day [4], which is the lowest rate since 2011. Moreover, from March 2020, Russia refused to reduce oil production according to the OPEC's agreement, which caused a price war between Saudi Arabia and Russia. The market panic led to a huge slump in a grade of oil price, like brent crude and The West Texas intermediate, and stock market crash [5]. In January 2021, the oil industry is recovering from COVID and oil price is rising due to the reduction of oil output [6].

CNOOC LTD is a crude oil and natural gas producer from China. It is also China's largest producer of offshore crude oil and a major subsidiary of China National Offshore Oil Corporation (CNOOC). Obviously, CNOOC is one of the leading corporations in this industry.

At this critical moment, the political conflict between China and the United States caused some unexpected things to happen. CNOOC received a delisting notice from the New York Stock Exchange[7]. The essay will explore the impact of this delisting notice on the future 
development of CNOOC, and estimate the development of CNOOC in the next few years, so as to make reasonable investment recommendations for investors. We have mainly studied CNOOC's operating and financial situation. By comparing specific data changes between years, we can make a brief assessment of the company's current state of development. We are particularly concerned about the data changes from 2019 to 2020 because we want to know exactly what specific impact the new crown outbreak and friction between China and the United States have on CNOOC and whether it will continue to affect CNOOC's development in the long term. The way we study the correlation between these effects is to compare data changes over time with external influences. As a public company, there is a lot of data and news resources are readily available, which also provides great convenience for the development of our work. Based on the results of our research, CNOOC was hit hard during the outbreak, mainly due to the rapid decline in turnover. The impact of political friction between China and the United States is still not obvious, but it is also one of the unstable factors affecting the company's development in the future. Our research also found that CNOOC's own profitability is assured. Because the performance of indicators representing profitability is still excellent throughout the market. But the company's profitability in the overall market performance is not satisfactory, can only be in the industry's lower and middle levels. But it is not difficult to draw a relatively optimistic forecast prospect when we associate the data research conclusions on CNOOC's profitability with the data research conclusions on profitability scale. Because CNOOC's profitability is trustworthy, the smaller size of its current performance is also due to the impact of the outbreak. So we can reasonably speculate that the future $\mathrm{CNOOC}$ in the scale of earnings there is still a larger room for growth, in the stock price performance is to experience a sustained rise, which is a worthy opportunity for investors to grasp.

\section{CURRENT OPERATION SITUATION ANALYSIS}

In December 2020, CNOOC was added in Defense Blacklist of alleged Chinese military companies by United States' government. In February 2021, NYSE started the process of delisting CNOOC according to the blacklist. Those sanctions had obvious impacts on CNOOC's stock. CNOOC's stock price decreased dramatically from $27^{\text {th }}$ November to $7^{\text {th }}$ December, when the information about sanctions was released. It was estimated that this impact will continue before restrictions is relaxed.

CNOOC is a Chinese state-run offshore crude oil and natural gas producer. Its core operating area includes Bohai, East China sea and South China sea. As a multinational company, CNOOC also has service in Africa, South America, North America and Europe. In terms of production, CNOOC's net production grows continually with consistent exploration work in recent 5 years. In 2020, its net production is around 528 million barrels of oil equivalent (mmboe), $67 \%$ of them are from China offshore. Meanwhile, CNOOV discovered 14 new oil and gas field and its Total proved reserves reached 5375 million boe. Affected by the pandemic, CNOOC's sales of crude oil and gas dropped by $30 \%$. The oil price war caused the realized oil price of CNOOC decreased around $35 \%$ in 2020 .

Table 1 CNOOC's net production, Sales of oil and gas and realized oil price in recent 3 years

\begin{tabular}{|c|c|c|c|}
\hline & 2018 & 2019 & 2020 \\
\hline $\begin{array}{c}\text { Net production } \\
\text { (mmboe) }\end{array}$ & 475.0 & 506.5 & 528.2 \\
\hline $\begin{array}{c}\text { Sales of oil and } \\
\text { gas } \\
\text { (CNY mm) }\end{array}$ & 185,872 & 197,173 & 139,601 \\
\hline $\begin{array}{c}\text { Realized oil price } \\
\text { (\$/bbl) }\end{array}$ & 67.22 & 63.34 & 40.96 \\
\hline
\end{tabular}

Source: CNOOC's annual report [8]

Note: "mmboe" represents million barrels of oil equivalent. "CNY mm" represents million in CNY. “\$/bbl” represents dollars per oilfield barrel.

\section{DATA ANALYSIS}

The table 2 below is data for the last five years of the five financial indicators related to CNOOC. Because of reduced capacity due to the Canadian wildfires in 2016 [9] and the downturn in oil prices in the global market, CNOOC's earnings figures for 2016 were relatively low, and we believe that the situation in this year was very accidental, with natural factors that exceeded expectations, so no special analysis was made.

Table 2 A portion of the CNOOC's data on operational capabilities

\begin{tabular}{|l|l|l|l|l|l|l|}
\hline & 2016 & 2017 & 2018 & 2019 & 2020 & Ranking in 2020 \\
\hline $\begin{array}{l}\text { gross profit(\$ in } \\
\text { million) }\end{array}$ & 11,572 & 28,467 & 21,968 & 23,309 & 13,910 & 68th in 81 \\
\hline EBITDA(\$ in million) & 9,577 & 15,110 & 19,029 & 20,378 & 15,638 & 66 th in 81 \\
\hline
\end{tabular}




\begin{tabular}{|l|l|l|l|l|l|l|}
\hline Revenue(\$ in million) & 21,099 & 28,648 & 32,999 & 33,491 & 24,083 & 69 th in 81 \\
\hline
\end{tabular}

Source: CNOOC's annual report; Yahoo finance

The last column ranks CNOOC's 2020 data in the same industry. Since CNOOC Ltd is listed in the U.S., we have obtained data from yahoo finance for all companies in the same industry. According to the yahoo finance, the number of companies in this industry is 81 . This ranking shows the figures from the greatest to the smallest. And through the indicator filter, the below results are presented. It can be seen that CNOOC's profitability indicators outperform most firms, but the ability to resist risks is not significant, which is in the middle of the industry level.

This data reflects changes in CNOOC's profitability and risk resistance. For the Great Recession in the oil industry in 2016, it doesn't really make much sense to look at the five-year growth rate. We are more concerned about the changes in the company's data indicators from 2019 to 2020. As we can see from the table 1, CNOOC's EPS, Return On Asset, Return On Equity all showed varying degrees of decline between 2019 and 2020, which represented the decline in shareholder returns and investment returns. EPS indicator falls by more than $83 \%$ as well, showing the biggest fall on scale in the last two years.

However, the Gross Profit Margin (GPM) and Debt to Asset Ratio (DAR) indicators continue to maintain a steady growth trend. The stability of GPM means that the profitability of the company's main business has not been negatively affected.

The Debt to Asset Ratio indicator represents the level of risk resistance of the enterprise, and the higher the value, the greater the risk to the external debt that the enterprise is saddle with. The further expansion of this data also shows that the current CNOOC is taking a greater capital risk to maintain the normal operation of the enterprise.

Table 3 A portion of CNOOC's data used to show the size of a business

\begin{tabular}{|l|l|l|l|l|l|l|}
\hline & 2016 & 2017 & 2018 & 2019 & 2020 & $\begin{array}{l}\text { Ranking in } \\
2020\end{array}$ \\
\hline EPS (CNY) & 0.01 & 0.55 & 1.18 & 1.37 & 0.23 & 16 th in 81 \\
\hline Return on asset & $0.1 \%$ & $4.0 \%$ & $7.7 \%$ & $8.1 \%$ & $3.5 \%$ & 17 th in 81 \\
\hline $\begin{array}{l}\text { Return on } \\
\text { equity }\end{array}$ & $0.2 \%$ & $6.5 \%$ & $12.5 \%$ & $13.6 \%$ & $5.6 \%$ & 17 th in 81 \\
\hline $\begin{array}{l}\text { Gross profit } \\
\text { margin }\end{array}$ & $87.0 \%$ & $85.2 \%$ & $84.9 \%$ & $87.3 \%$ & $92.3 \%$ & 13 th in 81 \\
\hline $\begin{array}{l}\text { Debt to asset } \\
\text { ratio }\end{array}$ & $66.8 \%$ & $62.4 \%$ & $62.6 \%$ & $69.1 \%$ & $69.8 \%$ & 48 th in 81 \\
\hline
\end{tabular}

Source: CNOOC's annual report; Yahoo finance

The table 3 reflects changes in the number of profits made by CNOOC. From 2019 to 2020, each indicator has shown different degrees of reduction. The difference was most marked by gross profit, which decreased by more than 40 percent. The changes in the data suggest that the size of CNOOC's operations will suffer a more severe negative impact in 2020, possibly due to a decline in production capacity due to the outbreak and U.S. sanctions.

The last column of data comes from the overall ranking of the industry. As can be seen, CNOOC's profit scale in the industry in the middle and lower reaches of the level.

Overall, these three indicators have not performed well across the industry. In CNOOC's own words, they have faced the "unprecedented challenges" in 2020. The main reason is the reduction in production of oil caused by corona virus and the sharp decline in oil prices in the early stages caused by a severe imbalance between supply and demand in the crude oil market. 
Combined with the analysis of the above two tables, the historical data of CNOOC performed well. One of the most prominent indicators is Gross Profit Margin, indicating CNOOC's excellent main business profitability. Worryingly, however, CNOOC's Return on Investment capacity has become lower and size of its operations has become smaller over the past year, with a slight decline in risk resistance and greater uncertainty ahead.

\section{CONCLUSION}

The essay has provided background information on the oil industry, an introduction of CNOOC's current operations and an analysis of CNOOC's financial data. It is clear to see that the oil industry is suffering a long-term recovery due to the reduction of production caused by COVID-19. In addition to the impact of the broader environment, the political risks to CNOOC itself are increasing. Moreover, the company's own financial data show that it is more profitable than most companies in the industry. Although the company is relatively small, it is at the mid- to lower-stream level in industry analysis. But the growing number of newly discovered oil reserves also suggests that the continued expansion of CNOOC's business size can be guaranteed for some time to come. Overall, CNOOC's performance exceeded the industries' average level, with risks coming mainly from outside, but in the long run these risks are manageable. In the future, cautious investors will need to focus on CNOOC's debt risks and on the political risks posed by China and the United States. These are the main uncertainties that CNOOC still faces. But we gain confidence in CNOOC's profitability through the data. Therefore, we recommend that investors choose CNOOC as the medium- and longterm investment target, instead of focusing on short-term factors fluctuations.

\section{REFERENCES}

[1] IEA. 2020. World Energy Outlook 2020. [online].[Accessed 29 March 2021]. Available from:

https://www.iea.org/reports/world-energy-outlook2020

[2] IEA.2020. Renewables 2020. [online].[Accessed 20 March 2021]. Available from:

https://www.iea.org/reports/renewables-2020

[3] Raval, A. \& Sheppard,D. 2020. Oil crash: why Saudi Arabia has started a global crude price war.[online]. [Accessed 20 March 2021]. Available from :https://www.ft.com/content/59dcba56-61a2-11eab3f3-fe4680ea68b5

[4] Cunningham, N. 2020. IEA: Oil Demand To Fall For First Time In A Decade.[online]. [Accessed 25
March 2021]. Available from: https://oilprice.com/Energy/Crude-Oil/IEA-OilDemand-To-Fall-For-First-Time-In-A-Decade.html

[5] Perper, R. and Bostock, B. 2020. Oil is down 21\% after its biggest drop in decades following Saudi price cuts that sparked a race to the bottom with Russia. [online].[Accessed 29 March 2021]. Available from:

https://www.businessinsider.com/oil-price-crashmarket-drop-global-price-war-futures-coronavirus2020-3

[6] Reportlinker. 2021. Oil And Gas Global Market Report 2021: COVID 19 Impact and Recovery to 2030. [online].[Accessed 15 March 2021]. Available from:

https://www.globenewswire.com/newsrelease/2021/02/01/2167113/0/en/Oil-And-Gas-

Global-Market-Report-2021-COVID-19-Impact-andRecovery-to-2030.html

[7] Bloomberg News. 2020. China's Three Big Telcos Slide on NYSE Move to Delist Shares[online]. [Accessed 11 March 2021]. Available from: https://finance.yahoo.com/news/china-three-bigtelcos-slide-042857628.html

[8] Yahoo finance. 2021. CNOOC's annual report. [online]. [Accessed 11 March 2021]. Available from:

https://finance.yahoo.com/quote/0883.HK/

[9] Dawson, C. 2016. Forest Fires Cut Into Canadian Oil Production. [online].[Accessed 29 March 2021]. Available from: https://www.wsj.com/articles/firescause-drop-in-canadian-oil-output-1462484697 